SAFETY OF PELVIC MASS EXTRACTION THROUGH COLPOTOMY IN WOMEN TAKEN TO LAPAROSCOPIC GYNAECOLOGIC INTERVENTIONS AT HOSPITAL DE SAN JOSÉ DE BOGOTÁ, COLOMBIA, 2016

\title{
Seguridad de la extracción de masas pélvicas por colpotomía en mujeres llevadas a laparoscopia ginecológica en el hospital de San José de Bogotá, Colombia, 2016
}

Rodrigo Ernesto Rodríguez-Ruiz, $M D^{1}$; Ángel David Miranda-Cruz, $M D^{1}$; César Augusto Rendón-Becerra, $M^{2}$; Catalina Agudelo-Restrepo, $M^{3}$

Received: August 17/17 - Accepted: July 3/18

\begin{abstract}
Objective: To describe the safety of colpotomy in terms of intra- and postoperative complications in women taken to laparoscopy for the removal of benign masses.

Materials and methods: Case series of patients with benign adnexal or uterine masses taken to laparoscopic surgery and removal of the specimen through colpotomy. The patients signed the informed consent. Patients with obliterated posterior cul-de-sac, narrow vagina, absence or uterus, deep endometriosis, inflammatory pelvic disease, masses of less than $4 \mathrm{~cm}$, were excluded. Consecutive sampling was used.
\end{abstract}

1 Associated instructors, Obstetrics and Gynaecology Department, Fundación Universitaria de Ciencias de la Salud (FUCS), Hospital de San José, Bogotá.

2 Resident of Endoscopic Gynaecologic Sugery, Obstetrics and Gynaecology Department, Fundación Universitaria de Ciencias de la Salud (FUCS), Hospital de San José, Bogotá. ceaure123@hotmail.co

3 Specialist in Endoscopic Gynaecologic Surgery, Fundación Universitaria de Ciencias de la Salud (FUCS), Hospital de San José, Bogotá.
Sociodemographic, clinical, qualitative and quantitative variables were studied by means of a descriptive analysis of the data. The research study was endorsed by the ethics committee of the institution. Results: During the study period, 12 procedures for the removal of benign pelvic masses using posterior colpotomy were performed. Mean age was 34.3 years (interquartile range - IQR: 29-39.5). Of these cases, 50\% were nulliparous women. Mean surgical time was 127 minutes (IQR: 90-150). There were no conversions to laparotomy, and there were no intra- or postoperative complications.

Conclusions: Posterior colpotomy is an option that can be considered in the removal of benign pelvic masses of more than $5 \mathrm{~cm}$ in size.

Key words: Morcellation, uterine myomectomy, laparoscopy, colpotomy, natural orifice endoscopic surgery.

\section{RESUMEN}

Objetivo: describir la seguridad de la colpotomía en mujeres llevadas a laparoscopia por masas 
benignas en términos de complicaciones intra y posoperatorias.

Materiales y métodos: serie de casos que incluyó pacientes con masas anexiales o uterinas benignas, sometidas a laparoscopia operatoria con extracción de la pieza quirúrgica mediante colpotomía, previo consentimiento informado. Se excluyeron pacientes con fondo de saco posterior obliterado, vagina estrecha, ausencia de útero, endometriosis profunda, enfermedad inflamatoria pélvica, masas menores de $4 \mathrm{~cm}$, muestreo consecutivo.

Se estudiaron variables sociodemográficas, clínicas, cualitativas y cuantitativas mediante un análisis descriptivo. La investigación fue avalada por el comité de ética médica de la institución

Resultados: durante el periodo de estudio se realizaron 12 extracciones de masas pélvicas benignas por colpotomía posterior. La mediana de la edad fue de 34,3 años (Rango Intercuartílico - RIC: 2939,5). El $50 \%$ de las pacientes eran nulíparas. La mediana de tiempo quirúrgico fue de 127 minutos (RIC: 90-150). No se realizó ninguna conversión a laparotomía. No se presentaron complicaciones intra ni posoperatorias.

Conclusiones: la colpotomía posterior es una alternativa por considerar en la extracción de masas pélvicas benignas cuando tengan un tamaño mayor a $5 \mathrm{~cm}$.

Palabras clave: morcelación, miomectomía uterina, laparoscopia, colpotomía, cirugía endoscópica por orificios naturales.

\section{INTRODUCTION}

Minimally invasive surgery is the approach of choice for the management of adnexal and pelvic masses of benign origin (1). It is considered to be a safe procedure when compared to the traditional open approach because of less postoperative complications, shorter length of stay, less postoperative pain, and faster return to activities of daily living $(2,3)$. Surgical specimens may be removed through natural orifices (trans-umbilical, trans-vaginal), mini-laparotomy, widening of the accessory surgical port, and morcellation (4).

However, in certain situations, such as the removal of large masses, extraction may pose a significant challenge to the gynaecologic laparoscopist $(5,6)$. In these cases, the surgeon may be forced to widen port incisions (trans-umbilical or trans-abdominal) in the skin or fascia, increasing the risk of postincisional herniation, surgical wound infection, postoperative pain, and poor cosmetic result (7, 8). It is worth remembering that the laparoscopic technique must be safe for the patient, minimise the risk of abdominal contamination, and allow for the adequate pathology study of the specimen. Consequently, colpotomy could be an option for the removal of moderate-sized masses $(5,9,10)$.

Colpotomy consists of performing an opening in the posterior vaginal cul-de-sac by means of an incision at the level of the uterosacral ligaments using monopolar energy. The idea is to use the vagina as a natural orifice for removing pathology specimens of varying sizes $(6,10)$. However, it is used infrequently given that there are other electrical or manual morcellation techniques that can be used to reduce the size of the specimens. Moreover, it is still controversial given the risks of infection, effect on sexual function (dyspareunia), and the technical difficulty for surgeons who are not used to perform this intervention $(4,9,11)$.

It is important to be able to select the most adequate extraction site in accordance with the size of the specimen. The different approaches are described in the literature, but the transvaginal approach is seldom used because it requires additional training in endoscopic surgery (mass decompression, vaginal morcellation, widening of accessory ports), endosuturing skills, and knowledge of the pelvic anatomy. Although colpotomy in international referral institutions is a relatively safe technique with a low prevalence of complications, 
in Latin America or in Colombia there are only a few case reports and no studies related to the clinical outcomes, complications or safety of this procedure. The purpose of this study is to provide information on the safety of this procedures in benign gynaecologic disease and its objective is to describe intra- and postoperative complications of colpotomy in women taken to laparoscopic gynaecologic surgery for the removal of benign masses.

\section{MATERIALS AND METHODS}

Design and population. Case series that included patients 18 years of age or older who presented with adnexal masses or benign uterine disease larger than $5 \mathrm{~cm}$ confirmed by diagnostic imaging, and a wide vagina, and who were taken to laparoscopy and agreed to participate by signing the informed consent. Excluded were patients with posterior cul-de-sac obliteration due to severe adhesions syndrome, deep endometriosis, or pelvic inflammatory disease grades II or III.

The study was conducted between February 1 and November 30, 2016, at the San Jose Hospital in Bogotá, a private, high-complexity, national referral centre that serves populations of the contributive and subsidised social security regimes in Colombia. Consecutive sampling of the patients who met the selection criteria was used for enrolment in the study.

Procedure. All patients with a diagnosis of benign adnexal or uterine masses were referred to the endoscopic gynaecologic surgery team and each patient was assessed to check compliance with the selection criteria. Patients were then interviewed by trained staff (subspecialty residents) using a semistructured questionnaire designed by the researchers, reviewed by experts and adjusted in accordance with the pilot test. Information contained in the institutional clinical record was also included.

The surgical technique was standardised and the entire surgical team (5 surgeons) were capable of performing the procedure. Laparoscopic surgery was performed using a $10 \mathrm{~mm}$ umbilical port as the main port, and two or three $5 \mathrm{~mm}$ trocars located in both iliac crests and right or left flank. Once the specimen was fully detached from the abdominal or pelvic support, the retrieval device (bag) was introduced through the main port. A uterine manipulation device fitted with a Koh cup $^{\mathrm{TM}}$ was used as a guide for location and marking in order to expose the posterior sac. A 1-3 cm transverse incision (culdotomy) was made with monopolar energy in the space between the two uteropelvic ligaments. With the help of laparoscopy forceps in the pelvic cavity and a speculum in the vaginal cavity, the edges of the bag were exposed and the entire material was removed. In those cases in which it was necessary, the specimen was cut with scalpel or scissors in order to reduce its size so that it could all be removed through the vaginal incision. Once all the specimens were removed, culdotomy was closed using 2-0 absorbable barbed suture, and peritonisation was performed. The peritoneal cavity was irrigated and drainage suction was applied in order to confirm haemostasis (Figure 1). Finally, as is usual in any laparoscopic procedure, trocars were removed under direct vision and fascial closure was performed if needed. All the patients received prophylactic antibiotics in accordance with the institutional protocol.

All patients were instructed to avoid intercourse for at least 2 weeks following surgery, and were asked to come back for follow-up 8 and 42 days after the procedure. During the follow-up visits they were asked about the presence of vaginal bleeding (quantity, foul smell), dyspareunia, fetid vaginal discharge, and other specific questions related to sexual activity such as changes after surgery, presence of pain or loss of sensation during intercourse.

The following variables were measured: age in years, weight in kilograms, height in centimetres, length of the surgical procedure (minutes), size 


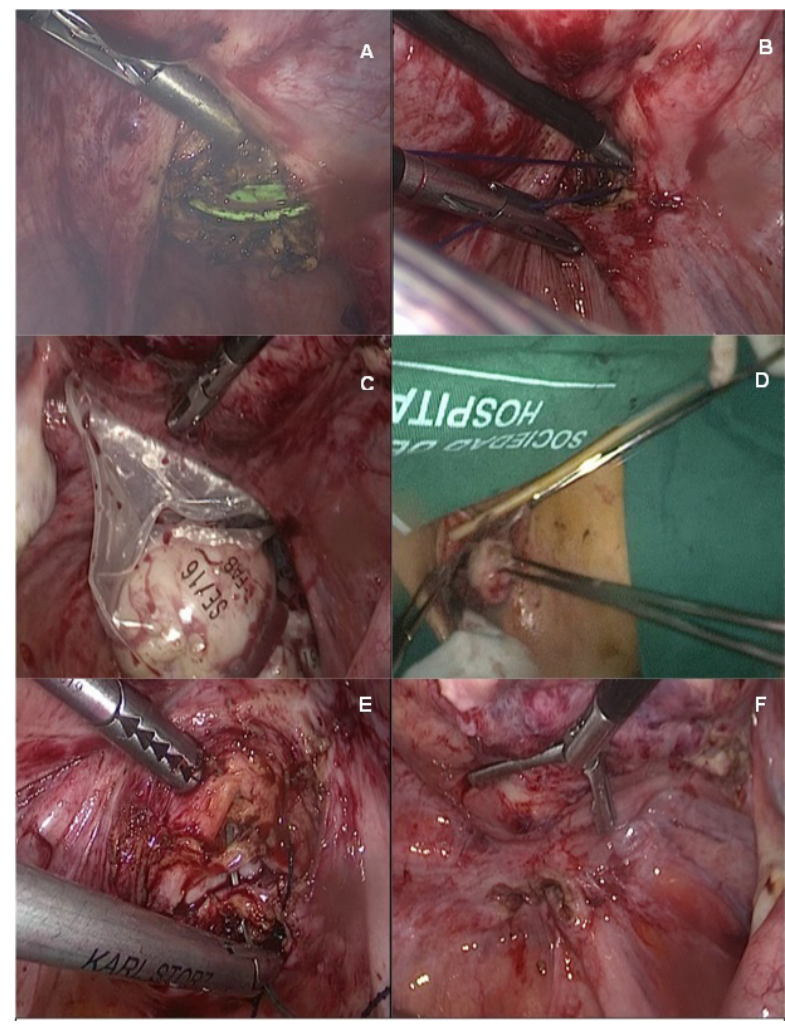

Figure 1. Description of the surgical procedure

a. Opening of the posterior sac using monopolar energy and uterine manipulator cup as guidance.

b. Passing pulling threads for vaginal extraction of the bag.

c. Passing the bag through the posterior cul-de-sac.

d. Vaginal extraction of the specimen (myoma in this case).

e. Closing the posterior cul-de-sac using barbed suture.

f. Final view of closed colpotomy.

Source: Authors.

of the mass found intra-operatively (millimetres), number of vaginal deliveries, menopausal status, indication for surgery (myomectomy, cystectomy, oophorectomy), postoperative complications (fever, wound infection, pelvic infection, dyspareunia, abscess or collection, micturition dysfunction, ileus, prolapse, reintervention, readmission, conversion to laparotomy).

Statistical analysis. A descriptive analysis of the data was performed using the Stata 13 software package. Qualitative variables are shown as absolute and relative frequencies, and quantitative variables as means and inter-quartile ranges.
Ethical considerations. The study was endorsed by the ethics committee of San José Hospital in Bogotá, as recorded in Minutes No. 22 of December 2, 2015. Data confidentiality was ensured.

\section{RESULTS}

Between February and November, 2016, 150 patients were identified as candidates for entering the study. Initially, 95 patients did not meet the inclusion criteria. In total, 55 patients were included for the surgical procedure, but 43 were excluded from the study because of intra-operative findings: 13 were found to have obliteration of the vaginal cul-de-sac, 15 had deep endometriosis of the rectovaginal septum, and 15 had severe adhesions syndrome. In the end, 12 patients met the inclusion and exclusion criteria (Figure 2). There were no losses to follow-up. Mean age was 34.4 years (IQR: 29-39.5), mean weight $56.5 \mathrm{~kg}$ (IQR: 53-60.5), median height $159.2 \mathrm{~cm}$ (IQR: 155-165), median surgical time $127.9 \mathrm{~min}$ (IQR: 90-150), median size of the pelvic mass $54.4 \mathrm{~mm}$ (IQR: 40-59) (Table 1). Of the patients, $50 \%$ had had a previous vaginal delivery and $41.6 \%$ were nulliparous. Of the surgical indications, $66.6 \%(n=8)$ were uterine fibromas (myomectomy) and the remaining 33.3\% $(n=4)$ were adnexal disease (Table 1$)$. None of the procedures performed had to be converted to laparotomy or other techniques for mass removal. There were no postoperative complications. On follow-up analysis on postoperative week 6 , none of the patients had dyspareunia or colpotomy wound dehiscence.

\section{DISCUSSION}

The results of our study of 12 women with benign adnexal or uterine masses larger than $5 \mathrm{~cm}$ show that there were no intra-operative or post-operative complications.

The sample size is this study is similar to that of other published series: Dubuisson, with 15 cases of uterine myomas (12), Goldfarb, with 12 


\section{Figure 2. Flowchart of patients}

Candidates for entering the study for the removal of adnexal or uterine mass through a posterior colpotomy, San José Hospital, Bogotá, Colombia, 2016

Total number of patients with adnexal or uterine mass, $n=150$

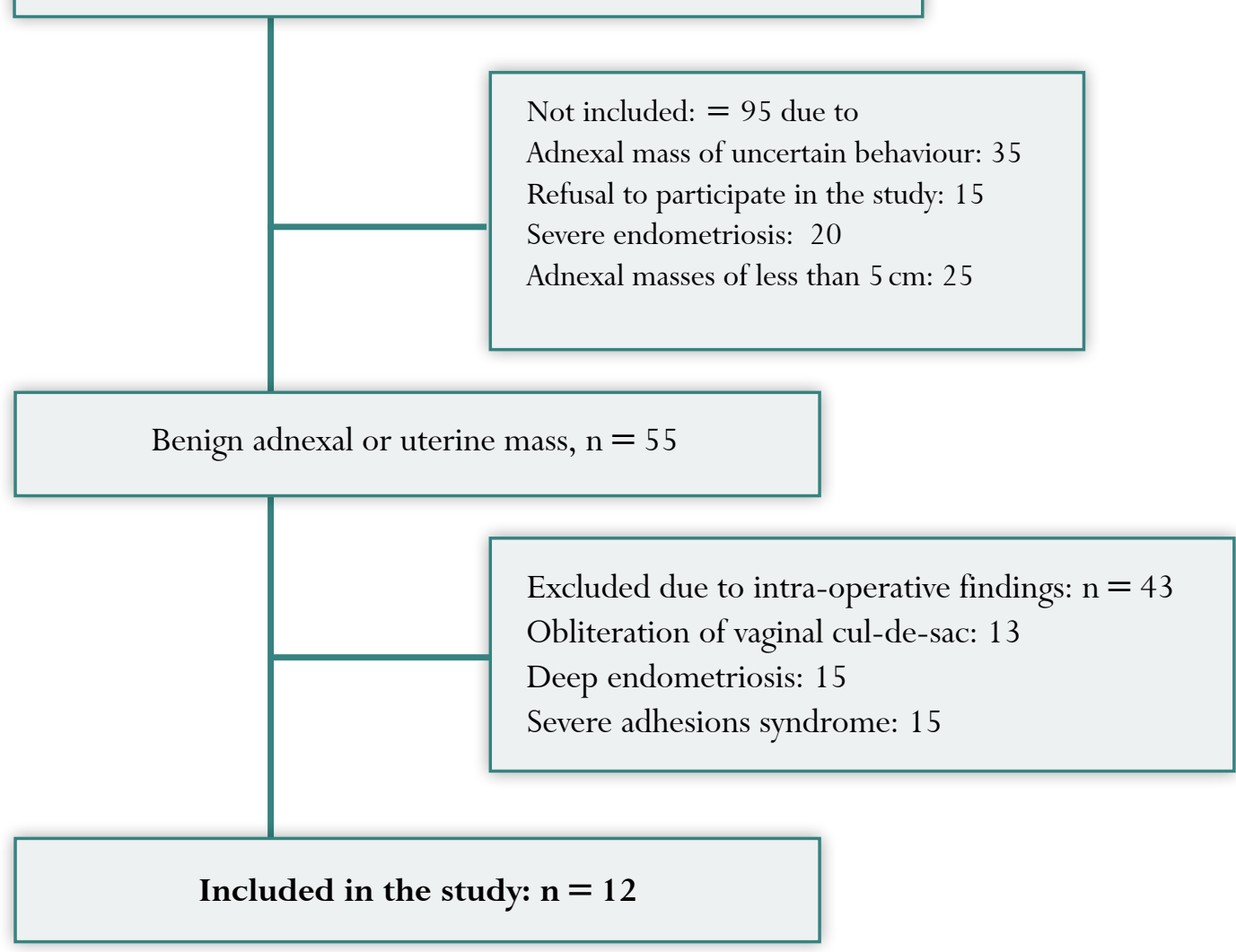

Source: Study data.

cases of myomatosis (13), and Duggal with 11 cases of dermoid cysts (14).

In our study, surgical time was $127 \mathrm{~min}$ (IQR: 90-120), longer than reported by other authors like Ghezzi in a controlled clinical trial of 66 patients comparing transumbilical $(\mathrm{n}=32)$ vs. transvaginal $(n=34)$ extraction of the specimens, where the surgical time was 56 minutes (SD +/- 20,5) for the transvaginal route vs. 64 minutes $(\mathrm{SD}+/-28)$ for the umbilical route $(p=0.16)(6)$. This difference may be attributed to the fact that our study was the first experience of the team with the use of this approach for the management of this disease, and to the size of some of the masses removed. Other retrospective cohort studies published by Ou et al., describing the use of colpotomy in myomectomy, report surgical times of 144 minutes (IQR: 110-160), similar to our series (15); additionally, surgical time in this cohort was much shorter $(p=0.05)$ when compared to morcellation (168 min) (IQR: 140-244) in cases of multiple myomatosis (15).

In the literature, sexual function and dyspareunia have been a source of speculation as relates to colpotomy; however, there is little evidence linking 


\section{Table 1.}

Clinical characteristics of women taken to laparoscopy and mass removal through colpotomy, San José Hospital, Bogotá, Colombia, 2016

\section{Variable}

Frequency

Percentage (\%)

\section{Deliveries}

\begin{tabular}{|c|c|c|}
\hline 0 & 5 & 41,67 \\
\hline 1 & 6 & 50 \\
\hline 2 & 1 & 8,33 \\
\hline \multicolumn{3}{|l|}{ Menopause } \\
\hline No & 12 & 100 \\
\hline \multicolumn{3}{|l|}{ Type of surgery } \\
\hline Myomectomy & 8 & 66,67 \\
\hline Cystectomy & 3 & 25 \\
\hline Oophorectomy & 1 & 8,33 \\
\hline
\end{tabular}

Source: Authors.

this procedure with those types of complications $(5,6)$. Uccella et al., in a retrospective analysis and systematic review of the literature, describe the experience of using the transvaginal approach for specimen extraction following various laparsocopic interventions $(n=230)$. These authors did a telephone evaluation on post-operative days 30 and 60 of 175 out of 230 women who had resumed their sexual activity (76.1\%) and did not find loss of vaginal sensation or post-operative dyspareunia (5). In our study, no associated dyspareunia was found 42 days postoperatively, but short-term follow-up is a limitation.

No associated complications were found in our study. However, related complications are reported in the literature, in particular the potential risk of infection with the trans-vaginal approach, mostly after hysterectomy, although it is rare $(<1 \%)(16)$; there are no data or frequency of complications associated with colpotomy for the extraction of pelvic masses. In a systematic review of the literature that included the largest number of patients
( $n=669$ cases) taken to endoscopic gynaecologic procedures with specimen removal through the transvaginal approach, there were 58 complications (6.5\%): 25 cases of postoperative fever (with or without signs of collection in the cul-de-sac) (2.8\%); 9 cases of cul-de-sac adhesions syndrome requiring reintervention with laparoscopic surgery (1\%); 8 cases of haemoperitoneum (1.1\%); 12 developed postoperative ileus or micturition dysfunction (1.2\%); another 4 included one case of uterine haematoma following myomectomy, fever secondary to medications, one case of cervical haematoma secondary to tenaculum impingement (0.4\%); only 1 patient required conversion to laparotomy (0.1\%). (5) It is important to mention that the absence of complications in our study is not attributable to the absence of risk but rather to the fact that the sample size is not big enough to allow to conclude that the rate of complications is low.

The strength of this study lies on the fact that the preoperative assessment and the technique were performed by an experienced endoscopic surgical 
team, suggesting standardisation; and the weaknesses are the type of design and the sample size.

\section{CONCLUSIONS}

Posterior colpotomy is an option that must be considered for the removal of benign pelvic massess larger than $5 \mathrm{~cm}$.

\section{ACKNOWLEDGEMENTS}

We are grateful to the endoscopic gynaecologic surgery team at San Jose Hospital for their support and their motivation to learn new surgical trends leading to improvements in patient outcomes.

To the Research Division of Fundación Universitaria de Ciencias de la Salud for its support with the execution and development of this project.

\section{FUNDING}

No funding was received for this project from any source.

\section{REFERENCES}

1. American College of Obstetricians and Gynecologists' Committee on Practice Bulletins-Gynecology. Practice Bulletin No. 174: Evaluation and management of adnexal masses. Obstet Gynecol. 2016;128:e2 10-26. https://doi.org/10.1097/AOG.0000000000001768

2. Medeiros LR, Stein AT, Fachel J, Garry R, Furness S. Laparoscopy versus laparotomy for benign ovarian tumor: A systematic review and meta-analysis. Int J Gynecol Cancer. 2008;18:387-99. https://doi. org/10.1111/j.1525-1438.2007.01045.x

3. Medeiros LRF, Rosa DD, Bozzetti MC, Fachel JMG, Furness S, Garry R, et al. Laparoscopy versus laparotomy for benign ovarian tumour. Cochrane Database Syst Rev. 2009;(2):CD004751.

4. Miller CE. Methods of tissue extraction in advanced laparoscopy. Curr Opin Obstet Gynecol. 2001;13: 399-405.

5. Uccella S, Cromi A, Bogani G, Casarin J, Serati M, Ghezzi F. Transvaginal specimen extraction at laparos- copy without concomitant hysterectomy: Our experience and systematic review of the literature. J Minim Invasive Gynecol. 2013;20:583-90.

6. Ghezzi F, Cromi A, Uccella S, Bogani G, Serati M, Bolis P. Transumbilical versus transvaginal retrieval of surgical specimens at laparoscopy: A randomized trial. Am J Obstet Gynecol. 2012;207:112.e1-6.

7. Chou L-Y, Sheu B-C, Chang D-Y, Huang S-C, Chen S-Y, $\mathrm{Hsu} \mathrm{W}-\mathrm{C}$, et al. Comparison between transumbilical and transabdominal ports for the laparoscopic retrieval of benign adnexal masses: A randomized trial. Eur J Obstet Gynecol Reprod Biol. 2010;153:198-202. https://doi.org/10.1016/j.ejogrb.2010.07.029

8. Wong LFA, Anglim B, Wahab NA, Gleeson N. A review of the open laparoscopic Hasson technique and retrieval of adnexal specimen via umbilicus. J Obstet Gynaecol. 2017;37:487-91. https://doi.org/10.1080 /01443615.2016.1269226

9. Ghezzi F, Raio L, Mueller MD, Gyr T, Buttarelli M, Franchi M. Vaginal extraction of pelvic masses following operative laparoscopy. Surg Endosc. 2002; 16:1691-6. https://doi.org/10.1007/s00464-0029043-z

10. Clark LE, Menderes G, Tower AM, Silasi D-A, Azodi M. A Simple approach to specimen retrieval via posterior colpotomy incision. JSLS. 2015;19(2). https://doi: 10.4293/JSLS.2014.00222.

11. Linke GR, Luz S, Janczak J, Zerz A, Schmied BM, Siercks I, et al. Evaluation of sexual function in sexually active women 1 year after transvaginal notes: A prospective cohort study of 106 patients. Langenbecks Arch Surg. 2013;398:139-45. https:// doi.org/10.1007/s00423-012-0993-x.

12. Dubuisson JB, Chapron C. Uterine fibroids: Place and modalities of laparoscopic treatment. Eur J Obstet Gynecol Reprod Biol. 1996;65:91-4.

13. Goldfarb HA, Fanarjian NJ. Laparoscopic-assisted vaginal myomectomy: A case report and literature review. JSLS. 2001;5:81-5.

14. Duggal BS, Tarneja P, Sharma RK, Rath SK, Wadhwa $\mathrm{RD}$. Laparoscopic management of adnexal masses. 
Med J Armed Forces India. 2004;60:28-30. https:// doi.org/10.1016/S0377-1237(04)80153-9

15. Ou C-S, Harper A, Liu YH, Rowbotham R. Laparoscopic myomectomy technique. Use of colpotomy and the harmonic scalpel. J Reprod Med. 2002;47:849-53.
16. Committee on Gynecologic Practice. Committee Opinion No 701: Choosing the route of hysterectomy for benign disease. Obstet Gynecol. 2017;129:e155-9. https://doi.org/10.1097/AOG.0000000000002112 